\title{
Quantitative computed tomography of the liver in dogs submitted to prednisone therapy
}

\author{
[Tomografia computadorizada quantitativa do fígado de cães \\ submetidos à terapia com prednisona] \\ L.A.V.S. Costa ${ }^{1}$, D.C. Oliveira ${ }^{1}$, B.F. Lopes ${ }^{1}$, A.B. Lanis ${ }^{1}$, \\ M.W. Teixeira ${ }^{2}$, F.S. Costa ${ }^{1,2^{*}}$ \\ ${ }^{1}$ Universidade Federal do Espírito Santo - Alegre, ES \\ ${ }^{2}$ Universidade Federal Rural de Pernambuco - Recife, PE
}

\begin{abstract}
The aim of this study is to evaluate the possible alterations in radiodensity of the hepatic parenchyma and spleen resulting from the corticotherapy with prednisone, correlating these findings with serum biochemical hepatic transaminase activity. A clinical trial was performed on eight healthy dogs with the intent of evaluating possible hepatic alterations after prednisone therapy using quantitative computed tomography. All animals received prednisone orally at a dose of $2 \mathrm{mg} / \mathrm{kg}$ of weight for 30 days. The radiodensity of the liver and spleen was determined before and after the period that the medication was administered. An increase in the radiodensity of the hepatic parenchyma between the initial and final experimental stages was observed. In the present study the existence of early hepatic alterations were verified, which are compatible with glycogen storage.
\end{abstract}

Keywords: dog, computed tomography, glycogenosis, radiodensity, glucocorticoid

\section{RESUMO}

O objetivo deste estudo é avaliar as possíveis alterações na radiodensidade do parênquima hepático e esplênico decorrentes da corticoterapia com prednisona, correlacionando estes achados com níveis séricos de transaminase bioquímicas hepáticas. Um ensaio clínico foi realizado em oito cães sadios com o objetivo de avaliar possíveis alterações hepáticas após a terapia com prednisona por meio de tomografia computadorizada quantitativa. Todos os animais receberam prednisona por via oral na dose de $2 \mathrm{mg} / \mathrm{kg}$ de peso por 30 dias. A radiodensidade do fígado e do baço foi determinada antes e após o período em que a medicação foi administrada. Foi observado aumento da radiodensidade do parênquima hepático entre os estágios iniciais e finais do experimento. No presente estudo, foi verificada a existência de alterações hepáticas precoces, que são compatíveis com o acúmulo de glicogênio.

Palavras-chave: cão, tomografia computadorizada, glicogenose, radiodensidade, glicocorticoide

\section{INTRODUCTION}

Glucocorticoids represent a group of drugs used in veterinary medicine for the treatment of several clinical signs and illnesses due to its antiinflammatory and immunosuppressive actions, as part of the antineoplastic treatment in chemotherapeutic protocols and in the treatment

Recebido em 25 de junho de 2011

Aceito em 19 de abril de 2013

*Autor para correspondência (corresponding autor)

E-mail: fabianosellos@hotmail.com of paraneoplastic syndromes (Cohn, 2005). Prednisone is a synthetic steroid glucocorticoid with intermediary action, oral bioavailability of up to $100 \%$ and great anti-inflammatory power (Schäcke et al., 2002; Cohn, 2005). This medication acts on the metabolism of carbohydrates, increasing gluconeogenesis with the reduction of the peripheral use of glucose and the increase of the glycogen reserves, as well as 
promoting a notable hyperglycemic effect. In the protein an lipid metabolism, an increase of catabolism occurs (Lowe et al., 2007).

Despite the benefit afforded in several cases, a condition of metabolic toxicity and alterations resulting from the corticotherapy can occur, causing important side effects (Schäcke et al., 2002; Cohn, 2005; Lowe et al., 2007). About $70 \%$ of the glucocorticoids are metabolized in the liver and their pharmacodynamic characteristics can induce hepatopathies with a deposit of glycogen and/or lipids in the hepatocytes (Lowe et al., 2007), which can trigger laboratorial, ultrasonographic and histopathological alterations in dogs (Schäcke et al., 2002). In humans, it has been mentioned that in patients presenting conditions that promote the accumulation of glycogen, such as von Gierke's disease (Glycogenosis Type I), it is possible that a deposit of glycogen occurs in the liver parenchyma with consequent increase of its density (Doppman et al., 1982; Kishnani et al., 2011).

Computed tomography (CT) exams present a broad variety of indications for dogs and cats, becoming an important tool for the establishment of several diagnoses (Smallwood and George, 1993; Rockall et al., 2003; Nakamura et al., 2005; Ohlerth and Sharf, 2007; Teixeira et al., 2007). The evaluation of abdominal organs' radiodensity is widely performed in human patients (Leander et al., 2000; Tsujimoto et al., 2006, Kodama et al., 2007) and can be employed with high precision and reproducibility in animals, helping in the diagnosis of alterations in several organs (Ohlerth and Sharf, 2007, Teixeira et al., 2007; Costa et al., 2010). A recent study demonstrated the occurrence of steroid hepatopathy in a dog subjected to prolonged corticosteroid therapy, with an increase of the parenchymal liver radiodensity (Costa et al., 2011). The aim of this study is to evaluate the possible alterations in radiodensity of the hepatic parenchyma and spleen resulting from the corticotherapy with prednisone, correlating these findings with serum biochemical hepatic transaminase activity.

\section{MATERIALS AND METHODS}

This study is a matched-pair clinical trial approved by the Ethics and Animal
Experimentation Committee of the Universidade Federal do Espírito Santo (UFES), Brazil. In order to choose the experimental group, selection exams were performed, which involved a detailed clinical and ultrasonographic evaluation of the abdominal cavity, as well as hemograms, urine analyses and dosage of alanine transaminase (ALT), aspartate transaminase (AST), alkaline phosphatase (ALP), gammaglutamyl transferase (GGT), blood urea nitrogen (BUN), creatinine, total protein, albumin, cortisol, free $\mathrm{T} 4$ and total $\mathrm{T} 4$ serum levels. Eight non-neutered/non-spayed young dogs (four male and four female) with age ranging from 12 to 36 months, without distinction of breed and with body weight ranging from 10 to $15 \mathrm{~kg}$ were used. The animals were sheltered in individual kennels with access to sunlight, receiving water and premium dry food (Purina Pro-Plan, Nestlé Purina PetCare, Ribeirão Preto, SP, Brazil). The dogs were leash walked twice daily for approximately 15 minutes.

All exams were performed in two experimental stages. The initial stage (S0) corresponded to the first day of the experiment, just before prednisone, at a dose of $2 \mathrm{mg} / \mathrm{kg}$ of body weight, starting with oral administration every 24 hours. The medication was administered for 30 days, which corresponded to the final stage of the experimental protocol (S1), with new exams being conducted afterwards. The animals were weighed weekly and the administered doses of prednisone for each animal were adjusted as needed. By the end of the experimental period, a gradual tapering of the glucocorticoid doses was performed, with all animals being donated for adoption afterwards.

Blood samples were obtained by jugular venopuncture and immediately centrifuged. The serum levels of ALP were measured using the colorimetric method, using sets of specific commercial reagents. The serum levels of the ALT, AST and GGT were measured through the kinetic method, also using specific kits for enzymatic dosage.

In order to perform the helical computed tomography exam, the dogs were submitted to a 12 hour fast. Fluid therapy was instituted with a physiological solution at an infusion rate of approximately $10 \mathrm{~mL} / \mathrm{kg} / \mathrm{h}$, serving as an access 
path for the administration of the anesthetic medications. Pre-anesthetic medication consisted of intravenous administering of diazepam in $0.5 \mathrm{mg} / \mathrm{kg}$ of body weight, and general anesthesia was induced and maintained intravenously with propofol in a dosage of approximately $6 \mathrm{mg} / \mathrm{kg}$ of body weight. The dogs were placed in the exam table in right lateral recumbency.

Using a helical CT scanner (Hi-Speed FX/i CT Scanner, General Electric Medical Systems, Waukesha, WI, USA), $2 \mathrm{~mm}$ contiguous transverse images were acquired from the diaphragm dome to the iliac crests. Technical factors were $120 \mathrm{kVp}$ and auto $\mathrm{mA}$ at a speed of one rotation per second. To enhance the evaluation of the liver and spleen a narrow window was chosen (window width $=400$, window level $=40)$. The $\mathrm{CT}$ machine was properly calibrated before each exam for a better

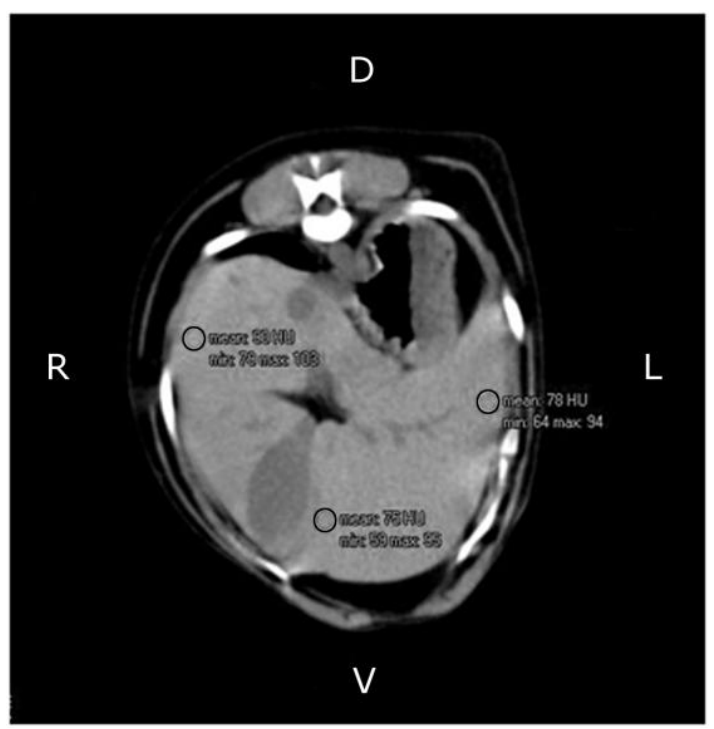

Figure 1. Transverse computed tomography image of a dog's abdomen demonstrating the selection of three regions of interest (small black circles) in the hepatic parenchyma in order to measure the hepatic radiodensity in Hounsfield units.

Samples for histological analysis were obtained after percutaneous ultrasound-guided biopsy to minimize the risks of the procedure and better focus of the collection region. Using needle-type $\mathrm{G}$ Tru-Cut 14, the fragment parenchyma collected was fixed at $10 \%$ formalin, processed in paraffin and stained with hematoxylin and eosin (HE), and slides prepared and analyzed in light microscopy and at 400 times magnification. standardization of the results. The original CT data were transferred as DICOM images to an image analysis software (eFilm version 2.1.2, Merge Healthcare, Milwaukee, WI, USA) to perform the image analysis.

Following the methodology described in humans by some authors (Leander et al., 2000), and adapted to dogs by some authors (Costa et al., 2010) we delineated nine regions of interest (ROIs) within the liver on the CT scans for each dog in three different slices. At each slice, three ROIs were randomly placed in the left lateral lobe, right lateral lobe and square lobe, avoiding large vessels and any focal lesions (Figure 1). We also drew three ROIs inside the splenic parenchyma, in the region of its largest volume, using the same methodology (Figure 2). Each ROI, in both hepatic and splenic parenchyma, measured approximately $25 \pm 0.1 \mathrm{~mm}^{2}$.

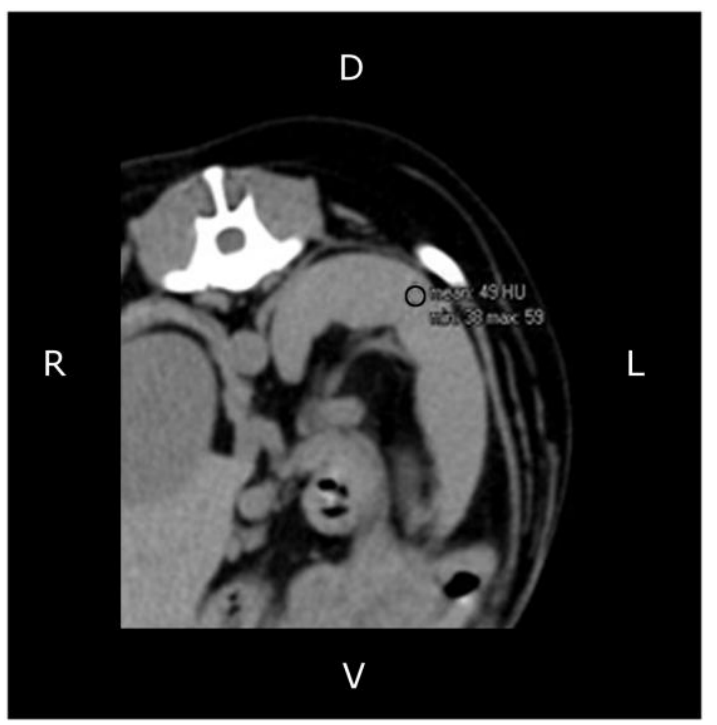

Figure 2. Transverse computed tomography image of a dog's abdomen demonstrating the selection of one region of interest (small black circle) in order to measure the splenic radiodensity in Hounsfield units.

The statistical analysis of the variables between the initial experimental stage (S0) and the final experimental stage (S1) was performed by a parametric statistical test (paired t-test), when the variables were normally distributed, and a nonparametric statistical test (Wilcoxon test), in the absence of normal distribution. The normality hypothesis was verified by the Shapiro-Wilk test 
and the asymmetry indexes. The level of significance used for all the tests was of 0.05 .

\section{RESULTS}

As displayed in Table 1, the results of our study demonstrated a significant increase in the radiodensity of the hepatic parenchyma between the initial and final experimental stages. The radiodensity of the splenic parenchyma did not vary statistically, but an increase in the difference of the degree of $\mathrm{x}$-ray attenuation was observed after a comparative analysis with the liver. Table 2 demonstrates that the serum levels of the ALT, AST and ALP enzymes increased significantly; however, according to one author (Morgan, 2008) only ASP and ALT serum levels were above the normal biochemistry values for dogs by the end of the experiment.

Table 1. Mean values of hepatic, splenic and renal radiodensity in Hounsfield units evaluated by helical computed tomography in eight dogs before and after therapy with oral prednisone at a daily dose of $2 \mathrm{mg} / \mathrm{kg}$ of body weight for 30 days

\begin{tabular}{lccccc}
\hline Evaluated area & \multicolumn{3}{c}{ S0 } & \multicolumn{3}{c}{ S1 } \\
\cline { 2 - 6 } & $x \pm$ sd & $m(\mathrm{IQR})$ & $x \pm$ sd & $m(\mathrm{IQR})$ & $P$ \\
\hline Liver $(\mathrm{HU})$ & $59.58 \pm 3.34$ & $60.08(4.79)$ & $65.95 \pm 3.67 \mathrm{a}$ & $66.04(4.59)$ & $0.013 \mathrm{~T}$ \\
Spleen $(\mathrm{HU})$ & $56.53 \pm 10.08$ & $53.76(7.62)$ & $54.03 \pm 4.29$ & $54.85(4.28)$ & $1.0 \mathrm{~W}$ \\
\hline
\end{tabular}

$x \pm$ sd, mean \pm standard deviation; $m(\mathrm{IQR})$, median (interquartile range); S0, initial stage; S1, final stage; $P$, probability. ${ }^{a}$ Values significantly different from the values in the initial stage. The Wilcoxon (W) test was applied for variables with the absence of normal distribution, and the paired t-test $(\mathrm{T})$ when the results presented normal distribution between the experimental stages.

Table 2. Laboratorial parameters evaluated in eight dogs before and after therapy with oral prednisone at a daily dose of $2 \mathrm{mg} / \mathrm{kg}$ of body weight for 30 days

\begin{tabular}{lccccc}
\hline Laboratorial & \multicolumn{3}{c}{$\mathrm{S} 0$} & \multicolumn{3}{c}{$\mathrm{S} 1$} \\
\cline { 2 - 6 } parameters & $x \pm \mathrm{sd}$ & $m(\mathrm{IQR})$ & $x \pm \mathrm{sd}$ & $m(\mathrm{IQR})$ & $P$ \\
\hline ALT(U/L) & $33.37 \pm 7.96$ & $32.00(13.50)$ & $70.25 \pm 32.07 \mathrm{a}$ & $59.00(50.00)$ & $0.004 \mathrm{~T}$ \\
$\mathrm{AST}(\mathrm{U} / \mathrm{L})$ & $22.25 \pm 7.53$ & $20.00(16)$ & $187.62 \pm 56.6 \mathrm{a}$ & $167.00(47)$ & $0.012 \mathrm{~W}$ \\
$\mathrm{GGT}(\mathrm{U} / \mathrm{L})$ & $6.06 \pm 6.13$ & $3.15(7.40)$ & $9.13 \pm 12.42$ & $3.82(5.74)$ & $0.40 \mathrm{~W}$ \\
ALP(U/L) & $23.75 \pm 14.77$ & $19.50(8.00)$ & $96.37 \pm 54.50 \mathrm{a}$ & $88.00(80)$ & $0.012 \mathrm{~W}$ \\
\hline
\end{tabular}

$x \pm$ sd, mean \pm standard deviation; $m$ (IQR), median (interquartile range); S0, initial stage; S1, final stage; $P$, probability; ALT, alanine transaminase; AST, aspartate transaminase; GGT, gammaglutamyl transferase; ALP, alkaline phosphatase; BUN, blood urea nitrogen.

${ }^{a}$ Values significantly different from the values in the initial stage. The Wilcoxon (W) test was applied for variables with the absence of normal distribution, and the paired t-test $(\mathrm{T})$ when the results presented normal distribution between the experimental stages.

\section{DISCUSSION}

Studies characterizing steroidal hepatopathy in dogs were performed in order to evaluate the ultrasonographic alterations of the hepatic parenchyma, observing an increase in ecogenicity after quantitative analysis by greylevel histogram, a fact attributed to the accumulation of glycogen in the hepatocytes (O’Brien et al., 1996; Lu et al., 1997; Syakalima et al., 1998). However, this isolated ultrasonographic finding is not enough for the orientation of a diagnosis of glycogen accumulation and requires invasive exams in order to establish a definitive diagnosis, since the increase in echogenicity of the hepatic parenchyma can also occur in the presence of lipidic accumulation.

The increase in the serum levels of ALT, AST and ALP enzymes, verified in the experimental group, are also described in dogs after the use of prednisone, characterizing the action of this medication on the liver (O'Brien et al., 1996; Lu et al., 1997; Syakalima et al., 1998). However, the significant increase in the serum activity of total ALP at the end of the treatment must not be attributed solely to the increase of hepatic ALP isoenzyme, since it has been stated that bone ALP isoenzyme and the one induced by glucocorticoids can contribute to the hyperphosphatasemia (Syakalima et al., 1998). 
In all animals marked changes were observed in the liver histopathology after individual analysis of each sample. The findings observed in all $\operatorname{dogs}$ on corticosteroid protocol in this study were increased cytoplasmic vacuolization, cytoplasmic granulation and size of hepatocytes. These findings support the presumptive diagnosis of glycogenosis radiodensity performed by estimating the hepatic parenchyma and are according to Rutgers et al. (1995), and Scherk and Center (2005) who stated that corticosteroid therapy promotes a significant increase in cytoplasmic vacuolation and accumulation of glycogen with a consequent increase in the size of hepatocytes.

In the last years $\mathrm{CT}$ has been considered an expanding imaging method in veterinary medicine. This technique provides valuable information, which complements those obtained by conventional imaging diagnosis methods such as radiographic and ultrasonographic exams (Rockall et al., 2003; Nakamura et al., 2005; Teixeira et al., 2007). The greatest advantage of CT for veterinary medicine according to some authors (Teixeira et al., 2007) is the speed in which the exam is performed, reducing movement artifacts and minimizing anesthetic time, being a non-invasive and safe method. Recently, the use of CT for the determination of bone mineral density in dogs treated with prednisone in daily dosage of $2 \mathrm{mg} / \mathrm{kg}$ of body weight, demonstrated that this drug is capable of promoting rapid alterations in the bone metabolism of this species (Doppman et al., 1982).

Glycogenosis promotes the increase of hepatic radiodensity, as has been verified in human patients (Tsujimoto et al., 2006; Kodama et al., 2007; Kishnani et al., 2011) and rats (Leander et al., 2000). The accumulation of hepatic glycogen is the main cause for dense livers in human patients. In vitro studies demonstrate that for each $1 \%$ increase in the concentration of hepatic glycogen, an increase in the $\mathrm{x}$-ray attenuation coefficient between 2.5 and 3.0 HU occurs in the CT exam (Tsujimoto et al., 2006). Thus, based on this study, it is possible to suggest an estimated increase of approximately $2 \%$ in the concentration of glycogen in the hepatocytes of the dogs used in this experiment.
Our dogs presented an increase in the variation of hepatic X-ray attenuation in comparison with the spleen at the final stage of the experiment, observing that the liver presented a mean radiodensity of $11.15 \mathrm{HU}$ higher than the spleen. In humans, a comparative evaluation of the $\mathrm{x}$-ray attenuation coefficient between these organs is of great importance in order to improve the clarification of the process, since in normal patients the liver is hyperattenuating in comparison to the spleen. The authors observed that in healthy patients, the liver, in non-contrastenhanced exams, presented itself with a radiodensity of approximately $3 \mathrm{HU}$ greater than the spleen's radiodensity (Leander et al., 2000).

It was possible to discard the occurrence of hepatic steatosis by the end of our experiment, since all the ROIs analyzed in the three slices had radiodensity values superior to those considered normal for dogs in the researched literature (Cáceres et al., 2006; Costa et al., 2010). CT in animals, as well as verified in humans, allows for the diagnosis of hepatic steatosis in a less invasive manner when compared with biopsy, laparotomy and laparoscopy techniques. Some authors (Ohlerth and Sharf, 2007) verified a significant reduction of hepatic radiodensity in cats with lipidosis when compared with the control group. According to reports, there is a decrease in hepatic radiodensity of approximately 1.0 to 1.5 $\mathrm{HU}$ for each $1 \%$ increase in the concentration of lipids in the organ (Leander et al., 2000; Kodama et al., 2007).

In humans, previously performed experimental studies demonstrate that approximately $20 \%$ of the patients with Cushing's syndrome present steatosis on the CT exam. Hepatic steatosis can occur in association with insulin resistance and obesity, two clinical signs commonly observed in Cushing's syndrome of both endogenous and exogenous etiologies (Tsujimoto et al., 2006).

Studies evaluating renal and hepatic damage resulting from the accumulation of glycogen were performed in dogs (Smallwood and George, 1993) and rats (Leander et al., 2000), in order to better understand the physiopathological aspects of von Gierke's disease in humans. The canine model for the induction of the disease was considered efficient, promoting clinical, laboratorial and pathological alterations similar 
to the ones observed in humans, enabling the characterization of renal and hepatic alterations in the experimental group (Smallwood and George, 1993).

Despite the advantage of the identification of the vascular structures, the radiographic contrast interferes directly in the organs' radiodensity, providing unreal results (Seeram et al., 2008). This way, it is important to emphasize that in this study, no contrast was used in the CT exams. We also highlight that aiming to provide greater precision for the comparative analysis of the evaluated areas the CT equipment was calibrated immediately before each exam.

\section{CONCLUSIONS}

We can conclude that the use of prednisone at a dose of $2.0 \mathrm{mg} / \mathrm{kg}$ of body weight for 30 days promoted an increase in hepatic radiodensity in dogs, suggesting an accumulation of glycogen in these organs. Caution in administering high doses of glucocorticoids is recommended, and it is important to monitor the patient that continually uses this drug. CT is a non-invasive, precise and efficient exam for the characterization of the potential side effects of the glucocorticoids in the liver of dogs.

\section{REFERENCES}

CÁCERES, A.V.; ZWINGENBERGER, A.L.; HARDAM, E. et al. Helical computed tomographic angiography of the normal canine pancreas. Vet. Radiol. Ultrasound, v.47, p.270278, 2006.

COHN, L.A.: Glucocorticoid therapy. In: ETTINGER, S.J.; FELDMAN, E.C. (Eds) Textbook of Veterinary Internal Medicine. St. Louis: Elsevier Saunders, 2005. p.503-508.

COSTA, L.A.V.S.; MAESTRI, L.F.P.; JÚNIOR, J.A.M. et al. Hepatic radiodensity in healthy dogs by helical computed tomography. Cienc. Rural, v.40, p.888-893, 2010.

DOPPMAN, J.L.; CORNBLATH, M.; DWYER, A.J.J. et al. Computed tomography of the liver and kidneys in glycogen storage disease. $J$. Comp. Assist. Tomo. v.6, p.67-71, 1982.
KISHNANI, P.S.; FAULKNER, E.; VANCAMP, S. et al. Canine model and genomic structural organization of glycogen storage disease Type Ia (GSD Ia). Vet. Pathol., v.38, p.83-91, 2001.

KODAMA, Y.; NG, C.S.; WU, T.T. et al. Comparison of CT methods for determining the fat content of the liver. Am. J. Roentgenol., v.188, p.1307-1321, 2007.

LEANDER, P.; MANSSON, S.; PETTERSSON, G. Glycogen content in rat liver: Importance for CT and MR imaging. Acta Radiol., v.41, p.9296, 2000.

LOWE, A.D.; GRAVES, T.K.; CAMPBELL, K.L. et al. A comparison of the diabetogenic effects of dexamethasone and prednisolone in cats. Vet. Dermatol., v.19, p.340-347, 2007.

LU, Z.F.; ZAGZEBSKI, J.A.; O'BRIEN, R.T. et al. Ultrasound attenuation and backscatter in the liver during prednisone administration. Ultrasound Med. Biol., v.23, p.1-8, 1997.

MORGAN, R.V. Handbook of Small Animal Practice. St. Louis: Elsevier Saunders. 2008. $312 \mathrm{p}$

NAKAMURA, M.; CHEN, H.M.; MOMOI, Y. et al. Clinical application of computed tomography for the diagnosis of feline hepatic lipidosis. J. Vet. Med. Sci., v.67, p.1163-1165, 2005.

O'BRIEN, R.; ZAGZEBSKI, J.A.; LU, Z.F. et al. Measurement of acoustic backscatter and attenuation in the liver of dogs with experimentally induced steroid hepatopathy. Am. J. Vet. Res., v.57, p.1690-1694, 1996.

OHLERTH, S.; SHARF, G. Computed tomography in small animals: Basic principles and state of the art applications. Vet. J., v.173, p.254-271, 2007.

OLIVEIRA, D.C.; COSTA, L.S.V.S.; LOPES, B.F. Computed tomography in the diagnosis of steroidal hepatopathy in a dog: case report. Arq. Bras. Med. Vet. Zootec., v.63, p.36-39, 2011.

ROCKALL, A.G.; SOHAIB, S.A.; EVANS, D. et al. Hepatic steatosis in Cushing's syndrome: a radiological assessment using computed tomography. Eur. J. Endocrinol., v.149, p.543548, 2003. 
RUTGERS, C.; BATT, R.M.; VAILLANT, C.; RILEY, J.E. Subcellular pathologic features of glucocorticoid-induced hepatopathy in dogs. Am. J. Vet Res., v.56, p.898-907, 1995.

SCHÄCKE, H.; DÖCKE, W.D.; ASADULLAH, $\mathrm{K}$. Mechanisms involved in the side effects of glucocorticoids. Pharmacol. Therapeut. v.96, p.23-43, 2002.

SCHERK, M.A.; CENTER, S.A. Toxic, metabolic, infectious, and neoplastic liver diseases. In: ETTINGER, S.J.; FELDMAN, E.C. (Eds) Textbook of Veterinary Internal Medicine. St. Louis: Elsevier Saunders, 2005. p.1464-78.

SEERAM, E. Computed Tomography: Physical Principles, Clinical Applications, and Quality Control. Philadelphia: Elsevier Saunders, 2008. $458 \mathrm{p}$.

SMALLWOOD, J.E.; GEORGE, T.F. Anatomic atlas for computed tomography in the mesaticephalic dog: Thorax and cranial abdomen. Vet. Radiol. Ultrasound, v.34, p.65-84, 1983.

SYAKALIMA, M.; TAKIGUCHI, M.; YASUDA, J. et al. Comparison attenuation and liver-kidney contrast of liver ultrasonographs with histology and biochemistry in dogs with experimentally induced steroid hepatopathy. Vet. Quart., v.20, p.18-22, 1998.

TEIXEIRA, M.; GIL, F.; VAZQUEZ, J.M.; CARDOSO. L. et al. Helical computed tomographic anatomy of the canine abdomen. Vet. J., v.174, p.133-138, 2007.

TSUJIMOTO, T.; TAKANO, M.; NISHIOFUKU, M. et al. Rapid onset of glycogen storage hepatomegaly in a type- 2 diabetic patient after a massive dose of long-acting insulin and large doses of glucose. Internal Med., v.45, p.469-473, 2006.
SCHÄCKE, H.; DÖCKE, W.D.; ASADULLAH, $\mathrm{K}$. Mechanisms involved in the side effects of glucocorticoids. Pharmacol. Therapeut. v.96. p.23-43, 2002.

SCHERK, M.A.; CENTER, S.A. Toxic, metabolic, infectious, and neoplastic liver diseases. In: ETTINGER, S.J.; FELDMAN, E.C. (Eds) Textbook of Veterinary Internal Medicine. St. Louis: Elsevier Saunders, 2005. p.1464-78.

SEERAM, E. Computed Tomography: Physical Principles, Clinical Applications, and Quality Control. Philadelphia: Elsevier Saunders, 2008. $458 \mathrm{p}$.

SMALLWOOD, J.E; GEORGE, T.F. Anatomic atlas for computed tomography in the mesaticephalic dog: Thorax and cranial abdomen. Vet. Radiol. Ultrasound, v.34, p.65-84, 1983.

SYAKALIMA, M.; TAKIGUCHI, M.; YASUDA, J. et al. Comparison attenuation and liver-kidney contrast of liver ultrasonographs with histology and biochemistry in dogs with experimentally induced steroid hepatopathy. Vet. Quart., v.20, p.18-22, 1998 .

TEIXEIRA, M.; GIL, F.; VAZQUEZ, J.M.; CARDOSO. L. et al. Helical computed tomographic anatomy of the canine abdomen. Vet. J., v.174, p.133-138, 2007.

TSUJIMOTO, T.; TAKANO, M.; NISHIOFUKU, M. et al. Rapid onset of glycogen storage hepatomegaly in a type- 2 diabetic patient after a massive dose of long-acting insulin and large doses of glucose. Internal Med., v.45, p.469-473, 2006. 